\title{
QUANDO A CARNE SE FAZ VERBO: A EMERGÊNCIA DE SIGNIFICADOS PELO (E NO) CORPO
}

\author{
Aline Aver Vanin \\ Universidade Federal de Ciências da Saúde de Porto Alegre \\ Porto Alegre, RS, BR.
}

\section{Resumo}

Por muito tempo, o corpo foi visto como um sustentáculo para a substância racional, a res cogitans cartesiana, que atribuía à mente todo o valor da racionalidade humana. Contudo, essa fragmentação do homem fez com que o corpo tivesse papel quase nulo para a racionalidade. Ao longo deste texto, discute-se uma retomada do lugar do corpo como campo semântico da razão: defende-se que é por meio dele que emergem grande parte dos conceitos, em especial os de emoções, categoria abstrata e historicamente relegada a um segundo plano no campo filosófico. É a partir da noção de uma cognição incorporada que se assumem os fundamentos para tratar dos processos de conceptualização e significação tão caros a áreas como as da Linguística Cognitiva.

Palavras-chave: Corpo; emoções; significação; conceitos; cognição.

\section{WHEN FLESH TURNS INTO WORDS: THE EMERGENCE OF MEANING THROUGH (AND IN) THE BODY}

\begin{abstract}
For a long time, the body was seen as a container for the rational substance, the Cartesian res cogitans, which attributed the value of the human rationality to the mind. However, this fragmentation of the man has given the body an almost null role to reason. Throughout this article, we discuss the place of the body as a semantic field for the reason: we advocate that it is through the body that most of the concepts emerge, especially those related to emotions, an abstract and historically denied category in the philosophic field. It is through the notion of an embodied cognition that the basis of conceptualization and conceptualization processes are assumed, especially in areas such as Cognitive Linguistics.
\end{abstract}

Key-words: Body; emotions; meaning; concepts; cognition.

Por muito tempo, a influência cartesiana separou o pensamento subjetivo do corpo, tornando este apenas sustentáculo para a fonte da razão. Consequência disso foi a visão de um homem fragmentado numa realidade em que ele apenas se coloca, mas não se constrói. Nessa perspectiva, a supervalorização da racionalidade e do pensamento diminuiu o papel das emoções na vida cotidiana, como se essas pudessem ser apenas uma parte desse homem. Contudo, contemplar um homem em pedaços é apenas vislumbrar sombras daquilo que ele real- mente pode ser. Neste texto, discutiremos o corpo como campo semântico para a construção de conceitos, especialmente os de emoções, categoria abstrata que tem sido relegada a um plano secundário e separado da razão. Veremos que tomar o corpo como referência para a condição cognitiva é entender o humano como um todo, que elabora significados para si e para a realidade, no fluxo intenso dos acontecimentos nos quais esses se instauram.

Para Lakoff e Johnson (1999), a incorporação da razão, como revelada pela Ciência Cognitiva, propõe

\footnotetext{
" Professora Adjunta de Língua Portuguesa do Departamento de Educação e Humanidades da Universidade Federal de Ciências da Saúde de Porto Alegre (UFCSPA). Doutora em Linguística pela Pontifícia Universidade Católica do Rio Grande do Sul. Seus interesses de pesquisa incluem as interfaces entre as áreas da Linguística Cognitiva, Filosofia da Linguagem, Estudos Culturais, Embodiment, Emoções e Saúde. Contato: alinevanin@ufcspa.edu.br.
} 
um entendimento sobre como mente e realidade se encaixam. Esse realismo corpóreo rejeita a visão cartesiana, sendo "enraizado na nossa capacidade de funcionar bem em nossos ambientes físicos": a mente assume uma forma encarnada. Apesar de serem corporalmente inscritos, os esquemas da experiência corporal não são exclusivos daqueles que passam por determinadas experiências: de fato, "nossa comunidade nos ajuda a determinar a natureza de nossa compreensão sempre coerente com a do nosso mundo ao redor" (GREINER, 2005, p. 43). Corpo e ambiente são, desse modo, co-determinados, em que um não se impõe sobre o outro: de acordo com Greiner (2005), o ambiente não é uma estrutura imposta, exterior aos seres vivos, mas faz parte de um processo de co-evolução com eles. $\mathrm{O}$ organismo é, portanto, sujeito e objeto da ação.

A crença em uma razão corpórea decorre do fato de que os mecanismos neurais e cognitivos que nos permitem perceber e mover são os que criam nossos sistemas conceptuais e modos de razão. Além disso, formas de inferências perceptiva e motora, também presentes em outras espécies de animais, são usadas e construídas pela razão (GREINER, 2005, p. 45). Essas inferências constituem parte da interpretação do mundo, em que o corpo é base da significação:

O corpo vivo se constrói como uma espécie de modelo semântico e este modelo emerge sempre da ação. Ele não a precede. Os conceitos são gerados ou tornados conscientes pelo corpo vivo, no fluxo da vida cotidiana, através de ações como mascar, urinar e respirar, entre outras. Assim, a ação vai criar novos conceitos e os novos conceitos incitam a ação. Existe portanto uma ligação indissolúvel entre o pensamento e a evolução e este nexo ocorre no corpo vivo. (GREINER, 2005, p. 66 - grifo nosso)

A hipótese da corporeidade da razão é fundamento para a Linguística Cognitiva, essencialmente experiencialista, em que as interações entre organismos e ambiente influenciam-se mutuamente, por meio das experiências enraizadas em aspectos físicos, perceptuais, sociais, culturais, emocionais, todos eles elaborados por meio do contexto situacional. Desse modo, não há uma realidade una e completa, mas aquela que se constitui pelos movimentos do corpo.

O realismo corpóreo que assumiremos aqui terá suas raízes nos trabalhos relacionados à Fenomenologia fundamentada em Dewey ${ }^{1}$ e Merleau-Ponty ${ }^{2}$. Lakoff e Johnson (1999) expõem que esses autores assumem que

(...) mente e corpo não são entidades metafísicas separadas, e que a experiência é encarnada, não etérea, e que quando usamos as palavras mente e corpo estamos impondo estruturas conceptuais limitadas artificialmente no processo integrado em andamento que constitui a nossa experiência. (p. 97)

Há um fluxo necessário entre o interior e o exterior como elementos que são faces de uma mesma moeda, mas nunca opostas.

Lakoff (1988) esclarece que o termo "experiencial", para o Realismo Corpóreo, é tomado em sentido amplo, englobando experiências sensoriomotoras, emocionais, sociais, culturais, bem como as capacidades inatas que dão forma a tais experiências e que as tornam possíveis. Contudo, o termo não deve ser compreendido como as impressões do sentido que dão forma a uma tábula rasa; nessa perspectiva, a experiência é ativa. Dados os corpos e as suas capacidades inatas de operar no mundo, a experiência comum é um elemento motivador, $\mathrm{e}$ não determinante, do que é significativo para o pensamento humano (LAKOFF, 1988, p. 120).

Para Lakoff e Johnson (1999, p. 4), a razão é evolucionária, pelo fato de, mesmo na sua forma mais abstrata, fazer uso da natureza animal de modo que a sua essência coloca o ser humano em um continuum. Do mesmo modo, a razão é também universal, tendo em vista ser uma capacidade compartilhada por todos os seres humanos. Essa razão, na maior parte do tempo, é inconsciente, estruturando-se conceptualmente por causa das experiências vividas. $\mathrm{O}$ entendimento de nossa estrutura conceptual desse modo oferece subsídios para explicar “(...) por que temos os conceitos que temos, e como nossa incorporação molda nosso raciocínio e a estrutura do entendimento que forma a base para o que tomamos ser verdadeiro" (LAKOFF; JOHNSON, 1999, p. 97-98). De modo semelhante, Greiner 
(2005) afirma que o fluxo incessante dos movimentos corpóreos "constrói novos vocabulários que são muito mais do que nomes vagando pelo mundo. Este 'novo vocabulário' reflete modos de organização dos pensamentos que organizam as ações corpóreas e o mundo" (p. 55). Em outras palavras, não é mais possível, como idealizavam as ciências cognitivas baseadas na ideia de uma mente modular, pensar em uma mente abstrata e etérea, com seus módulos operacionais que são ativados e se interligam para a execução de tarefas sintáticas em primeira instância; essa mente, em nossa concepção, é essencialmente corpórea.

Enfatiza-se a importância da experiência humana para esse paradigma e o papel crucial do corpo humano na organização cognitiva, numa relação de mútua influência e inextricabilidade. Para Lakoff (1987), o paradigma objetivista, em que o mundo está pronto, não podendo ser criado pelas mentes humanas, é falso: "as instituições são criadas pelas pessoas. Elas são específicas-da-cultura [culture-specific]. Elas são produto da mente humana" (p. 207).

Segundo Damásio (1996, p. 117), "se nossos organismos fossem desenhados de maneiras diferentes, as construções que fazemos do mundo que nos rodeia seriam igualmente diferentes. Não sabemos, e é improvável que alguma vez venhamos a saber, o que é a realidade 'absoluta"'. A realidade é, de fato, uma das verdades à qual podemos ter acesso sob dada perspectiva, pela mediação da natureza de nossos corpos e do entendimento que dela extraímos. A verdade corpórea, como a denominam Lakoff e Johnson (1999), não é puramente objetiva, tendo em vista a compreensão individual ligada inextricavelmente às interações corpóreas, e nem é inteiramente subjetiva. Nesse sentido, não há mais a noção da existência de um mundo objetivo, como assumido pela filosofia tradicional; os objetos não são externos a nós, independentes de nossas capacidades perceptivas e cognitivas, mas fazem parte do que somos. A ideia de uma objetividade parcial vem da compreensão de que o conhecimento é o resultado de uma interpretação em andamento que emerge de nossas capacidades de entender. Essas estão enraizadas nas estruturas de nossa corporificação biológica, mas são vivenciadas dentro de um domínio de ação consensual, compartilhada, e cultural.
A hipótese da corporeidade, em Lakoff e Johnson (1999), vê os conceitos abstratos como construídos por meio de um mapeamento de domínios mais físicos. Os autores chegam a afirmar que há tipos naturais de experiência, e não só de experiência do corpo, mas com o ambiente físico e com a cultura. Contudo, mencionam de maneira geral o fato de que esses elementos são relevantes para a corporeidade, deixando de desenvolver noções como a relação do homem com o mundo por ele criado e com os outros. Os recentes trabalhos de Kövecses (2005, 2010a, 2010b, 2010c, 2011) tratam das diferentes dimensões contextuais, em que os cenários físicos, culturais, sociais e também o fluxo discursivo estão envolvidos. Contudo, de certa forma, o autor não aborda tais aspectos como sendo também básicos para a corporeidade. Nesse sentido, é preciso ter em mente que a corporeidade desenvolvese não só porque temos percepções a partir do corpo, mas que o envolvimento desse corpo com estímulos externos do ambiente e da cultura em que se insere são também peças-chave na construção de significados para o mundo.

Jensen de López e Sinha (1998, apud ROHER, 2001) esclarecem que a concepção central de corporeidade na Linguística Cognitiva deve ser revista: em seu estudo, revelam que a interação com o espaço é tão básica quanto a relação de elementos do corpo em si mesmo. Além disso, ao assumir a interpretação da hipótese da corporeidade apenas tomando o corpo per se, como se isolado do ambiente, a Linguística Cognitiva estaria ignorando práticas culturais de extrema importância para a conceptualização. Desse modo, as relações do corpo consigo mesmo, com o mundo e com os outros de sua cultura, numa relação intersubjetiva, é base para a construção e compreensão da realidade. Segundo Roher (2001), o estabelecimento de referência compartilhada é algo que toma forma em meio a um contexto cultural; o corpo se desenvolve em interação com as pessoas e a cultura em que se insere, bem como em interação com o espaço.

Rohrer (2001, p. 60-62) sustenta que a questão da corporeidade pode ser abordada sob diferentes sentidos e níveis de investigação: 
i. a partir de seu significado fenomenológico, isto é, no papel dos nossos corpos em moldar nossas auto -identidades e nossa cultura através de nossos atos de consciência;

ii. tomando por referência as contribuições culturais e o contexto no qual corpo, cognição e linguagem emergem e se situam;

iii. a partir de uma perspectiva filosófica que vai contra a tradição cartesiana de separação entre mente e linguagem;

iv. referindo-se ao inconsciente cognitivo, nos termos de Lakoff e Johnson (1999);

v. em um sentido neurofisiológico, em que o termo "corpóreo" pode referir a estruturas neurais particulares e específicas;

vi. para relacionar modelos neurocomputacionais de linguagem, principalmente aqueles relacionados a metáforas conceptuais;

vii. "corpóreo" pode referir-se às mudanças no desenvolvimento pelas quais o organismo passa na transformação de criança até adulto;

viii. pelo curso evolucionário do desenvolvimento que as espécies têm passado durante o curso de sua história genética;

ix. no sentido de "corporeidade" dado por Lakoff e Johnson (1980), em que há uma forte delimitação na unidirecionalidade metafórica, em que um domínio-fonte mais corpóreo é usado para entender um domínio-alvo abstrato;

x. em que o significado é enraizado em termos de escolha de um número finito de domínios-fonte semanticamente autônomos (conforme Lakoff e Turner, 1989), isto é, em que o sentido de corporeidade seria uma generalização sobre os tipos de domínios conceptuais básicos que geralmente servem de domínios-fonte.

Seguindo essa interpretação, explicam Varella, Thompson e Rosch (1991) que mundo e "sujeito apercebedor" especificam-se mutuamente, numa negociação entre um mundo externo, físico, e um mundo parcialmente idealizado ao longo da vida, o qual se ajusta e se modifica, projetando-se na linguagem. De acordo com esses autores, é necessário ultrapassar essa geografia lógica de interior versus exterior através do estudo de uma cognição que não seja a de recuperação de concepções prontas ou de uma projeção, mas de ação incorporada. Os autores salientam que "a cognição depende dos tipos de experiência obtidos pelo fato de se ter um corpo com várias capacidades sensoriomotoras" e que "essas capacidades individuais estão inscritas em um contexto biológico, psicológico e cultural mais abrangente" (VARELLA; THOMPSON; ROSCH, 1991, p. 172-173). Além disso, o termo ação, em ação incorporada, enfatiza que os processos sensoriomotores, a percepção e a ação não estão apenas ligados, mas inserem-se em uma condição de evolução inextricável. Nesse sentido, assumimos desde já que não é possível dicotomizar as relações sociais (e por sociais entendemos, neste momento, a diversidade de relações em uma comunidade de fala) e os aspectos cognitivos da construção do significado: a cognição, essencialmente corpórea, é sempre fundada ou situada socialmente - trata-se, portanto, de uma sociocognição (VEREZA, 2010). Para Bezerra (2001), mente, corpo e mundo são indissociáveis e é por esse fato que não há distinções ontológicas entre eles:

No entendimento pragmático, a linguagem não produz nenhuma ruptura abissal entre sujeito e a realidade, entre o ser e o mundo. Nele, o mundo é aquilo com que estamos em contato o tempo todo. A linguagem não cria nem dele nos afasta, mas permite uma relação diferente com ele. A experiência humana é um interjogo em que o mundo age de maneira permanente e complexa sobre nós e nós sobre ele: é possível descrever esse processo como o emergir - nosso e do mundo - na experiência. (BEZERRA, 2001, p. 31-32, itálico do autor) 
Wilson (2002) elucida que os processos cognitivos estão enraizados profundamente nas interações do corpo com o mundo. Essa posição, segundo a autora, se desdobra em seis pontos distintos:

i. a cognição é situada (a atividade cognitiva tem seu lugar no contexto de um ambiente do mundo real, e envolve percepção e ação);

ii. a cognição é pressionada pelo tempo [time-pressured] (a cognição deve ser entendida conforme ela funciona sob as pressões da interação em tempo real com o ambiente);

iii. o funcionamento cognitivo é descarregado no ambiente (devido às limitações de nossas habilidades de processamento da informação, exploramos o ambiente para reduzir a carga de funcionamento);

iv. o ambiente é parte do sistema cognitivo (o fluxo de informações entre mente e mundo é tão denso e contínuo que a mente somente não é uma unidade significativa de análise);

v. a função da cognição é guiar a ação (os mecanismos cognitivos, tais como percepção e memória, dão sua contribuição para o comportamento situacional mais apropriado);

vi. a cognição "off-line" é baseada no corpo (a atividade da mente está enraizada em mecanismos que evoluíram para a interação com o ambiente) $)^{3}$.

Para a mesma autora, a quarta afirmação é profundamente problemática, tendo em vista que significa que "as forças que dirigem a atividade cognitiva não residem somente dentro da cabeça do indivíduo, mas ao invés disso são distribuídas pelo indivíduo e a situação enquanto eles interagem" (WILSON, 2002, p. 630). O problema residiria no fato de que, sendo ciência, e esta procurar por princípios e regularidades, seria necessário buscar delimitações para tratar das questões da cognição como um sistema. No entanto, segundo a proposta da mente corpórea, a cognição pode ser distribuída facul- tativamente, durante as interações, sendo aberta às modificações do ambiente. Por isso, não vemos essa característica como tão controversa: por estar profundamente arraigada ao corpo, a cognição se modifica conforme o fluxo de suas interações no mundo. $\mathrm{O}$ ambiente tem papel relevante na construção do próprio conhecimento enciclopédico, que é fundamental para a (re)construção de (novos) conceitos conforme a interação ocorre.

Assim, não possuímos uma mente, ou uma racionalidade, que está inserida em um corpo, pois somos o nosso próprio corpo. É o corpo que nos orienta e situa no mundo físico: não apenas estamos no mundo, como também somos o próprio mundo, pois é a partir do corpo que percebemos e damos significados ao que chamamos de realidade. Desse modo, sendo o mundo e parte dele, a nossa subjetividade só pode ser parcial, tocada pela nossa objetividade construída: "a subjetividade é tingida pelo corpo, ao mesmo tempo em que o corpo, realidade mundana, é atravessado por uma dimensão subjetiva, é o corpo vivido" (GIORDANI, 2009, p. 813). Segundo Greiner (2005), “(...) a fonte da subjetividade está sempre ligada à imagem de um organismo durante $o$ ato de perceber e de responder a uma entidade externa" e, desse modo, o que chamamos de subjetividade "pode emergir de qualquer cérebro capaz de construir uma representação simples de si-mesmo e, obviamente, com a capacidade de criar imagens e se transformar" (p. 81). Assim, não há uma subjetividade stricto sensu, encerrada em um só corpo e somente revelada por ele em seu self restrito; essa sempre dependerá de outro(s) corpo(s), e não só do "Em si" (self) nietzschiano. ${ }^{4}$

Os objetos, portanto, não estão prontos, dentro de nós, sem levar em conta fatores sociais e culturais - os quais, por sua vez, também são construtos da experiência. A linguagem não se relaciona aos conceitos internos à mente e nada mais. Para Sinha (1999), isso levaria a uma forma extrema de subjetivismo, no qual conceitos são totalmente desagregados do mundo ao qual eles se relacionam. Na verdade, os conceitos só existem porque eles servem como uma forma inevitável de entender o mundo, e eles emergem porque a nossa arquitetura conceptual é baseada no meio em que nossos corpos interagem, e na natureza desses corpos. Portanto, essa subjetividade é, também, construída de acordo com a 
mediação corpórea, inserindo-se em um mundo biológica, social e culturalmente compartilhado.

O que entendemos sobre o que é o mundo é determinado por muitas coisas: nossos órgãos sensoriais, nossa habilidade de nos movermos e de manipular objetos, a estrutura detalhada de nosso cérebro, nossa cultura, e nossas interações em nosso meio, pelo menos. O que nós tomamos como sendo verdade em uma situação depende de nosso entendimento corpóreo da situação, o qual é, por sua vez, moldado por todos esses fatores. (LAKOFF; JOHNSON, 1999, p. 102, grifo dos autores)

Essa verdade nada mais é do que fruto das nossas percepções e interações, e nada tem a ver com a verdade objetiva; de fato, ela é apenas uma noção parcial daquilo que construímos como objetividade e como subjetividade. A formação de conceitos é vista como uma construção compartilhada, intersubjetiva, em que tanto a mente quanto o mundo são elaborados. A consequência disso, dizem Evans e Green (2006), é que "nós só podemos falar sobre o que percebemos e concebemos (...)” (p. 46), e só podemos falar daquilo que é real para nós, ou seja, do que é constantemente moldado e ressignificado pelas interações cotidianas. Greiner (2005, p. 103) defende essa hipótese ao dizer que o fluxo das informações se dá pela construção mútua do particular e do coletivo o tempo inteiro.

Por ser o corpo a base para que os dados advindos da experiência se acomodem e se organizem para estipular perspectivas para o mundo, ele é influenciado e, ao mesmo tempo, influencia. O corpo é o lugar no qual os inputs de toda sorte se vão estabelecer e os conceitos são significados mediatamente: a constituição de si próprio e das coisas do mundo está em consonância com as relações intersubjetivas.

O corpo, em inextricável relação com a cognição, em atitudes interacionais - conscientes ou não - é capaz de fazer emergir conceitos inscritos na memória enciclopédica - cujo fundamento se dá pelas relações sociais, culturais, históricas, sensoriomotoras e, em grande medida, emocionais - para ser capaz de reformular, a cada movimento, as suas concepções, recriando constantemente, a partir da sua base experiencial, a própria rea- lidade. Veremos que essa experiência tem papel fundamental na constituição de uma objetividade parcial, que se desdobra em caminhos explicativos, os quais possibilitam direções variadas para a leitura do mundo.

\section{Falar sobre a experiência e objetivá-la: o domínio das emoções}

Ao afirmarmos que construímos a realidade, não queremos dizer que tudo o que existe é fruto unicamente de nossas operações cognitivas. Isso seria o mesmo que cair em um idealismo ingênuo. Está claro que o mundo existe antes mesmo de nós o habitarmos e essa condição permanecerá mesmo após perecermos. O que queremos dizer é que esse mundo diante de nós é diferente da tela que pintamos sobre ele. Nas palavras de Bezerra (2001, p. 18), "quando deixamos de nos perguntar sobre a existência ou não de um mundo prévio a nós e à linguagem, e passamos a nos perguntar quais objetos constituem esse mundo, ingressamos no domínio das descrições linguageiras e dos pontos de vista que elas acarretam". Dessa maneira, o mundo per se existe independentemente de nós, mas a sua delimitação, não.

Harder (1999) argumenta que a posição ontológica sustentada na relação entre fatos cognitivos de um lado e fatos sociais e funcionais de outro é o realismo, também chamado de objetivismo. O autor acrescenta que "há uma diferença importante entre ser um objetivista em relação ao mundo e ser um objetivista em relação ao significado" (p. 201). Citando Searle (1995), Harder afirma que, no primeiro caso, o mundo existe independentemente da percepção ou da compreensão do indivíduo; no segundo, acredita-se que os significados de palavras podem ser traduzidos em categorias "objetivas" independentes da mente. Tendo em vista que não se pode escapar da própria condição cognitiva, não é possível ter uma visão objetiva integral do mundo; só se pode estabelecer qual é a crença que se tem em relação a um objeto que colocamos em nosso recorte do mundo. Nesse sentido, o fato de outra pessoa encontrar-se em estado de raiva faria com que aquele que o percebe tenha apenas uma crença sobre a raiva que o outro sente, se esse sentimento de emoção tem um grau elevado ou não, quais as sensações o in- 
divíduo pode estar sentindo, e estabelecer uma relação com o contexto que desencadeou tal emoção, posto que as experiências de quem observa permitem-lhe definir aquele estado emocional.

Para Maturana (2001), experiência e explicação da experiência são elementos distintos da percepção, mas que se fundem a ponto de os descrevermos como se fossem um só. Para o autor, "a experiência nunca está em jogo. (...) O problema é sempre a explicação da experiência" (p. 43). Nós a expressamos linguisticamente, e essa deve ser aceita para ser realmente uma explicação de experiência. Maturana (2001) sugere a existência de dois caminhos explicativos para essa percepção: o primeiro, chamado objetividade sem parênteses, refere-se aos elementos que usamos para escutar, mas que existem independentemente da nossa observação. Nesse caso, podemos fazer distinção entre ilusão e percepção, já que esses elementos são independentes do ser. O escutar, aqui, se dá com elementos da experiência aceitos pelo indivíduo. Portanto, ao seguir o caminho explicativo da objetividade sem parênteses, tentamos ter acesso privilegiado à realidade que valida nossa ação, para a qual temos uma referência (MATURANA, 2001, p. 38). Nesse domínio dão-se discussões que envolvem conceitos compartilhados entre indivíduos, como as discussões ideológicas, as quais "colocam-se como posições experienciais ou filosóficas que pretendem ter acesso à realidade em si” (p. 40).

Já para o segundo caminho explicativo, a objetividade entre parênteses, a existência depende do observador, do eu. Assim, ao vivermos uma linguagem de objetos, falando sobre eles, reformulamos a realidade, que não existe independentemente de quem a observa. De fato, essa realidade só se faz presente por causa do observador e da linguagem que ele utiliza: não há uma realidade, pois ela se molda conforme o observador, que a interpreta e a descreve. Portanto, ao nos movermos através da linguagem, temos domínios de realidade distintos, que são assumidos conforme a escuta que fazemos. Se há discordância entre os interlocutores quanto ao que o conceito significa, então esses sujeitos estão em domínios de realidade diferentes, construídos por perspectivas distintas. Nesse caminho explicativo da objetividade entre parênteses, diz Maturana (2001), a corporalidade é nossa possibilidade, porque ela ocorre por meio da relação com o ambiente e com outros corpos; ela é legítima, porque é a partir da sua biologia que se pode explicar o observar, "é o que permite resolver o dilema tão antigo da relação mente-matéria" (p. 41), o qual é insolúvel na objetividade sem parênteses.

Nessa relação de objetividades, contudo, não se pode cair em um reducionismo; conforme o mesmo autor,

(...) objetividade sem parênteses e objetividade entre parênteses não são a antinomia objetivo-subjetivo. A objetividade entre parênteses não significa subjetividade, significa apenas 'assumo que não posso fazer referência a entidades independentes de mim para construir meu explicar.' (MATURANA, 2001, p. 35, grifo nosso)

Nessa concepção, movemo-nos entre essas duas objetividades, em domínios de realidade que se distinguem conforme os ouvimos. Acordamos quanto a um caminho explicativo ou outro no jogo interacional. Assim, explicações sobre a experiência não se configuram na verdade, mas em domínio(s) de verdade(s), que são elaborados discursivamente. No entanto, por pertencermos a uma cultura que se fundamenta em uma objetividade sem parênteses, a tendência é que essas explicações sejam potencialmente universais (transcendentais). Contudo, elas só podem ser universais no domínio da interação.

É importante ressaltar que, no caminho da objetividade sem parênteses, temos o que Maturana (2001) chama de domínio das ontologias transcendentes, em que se assume uma ontologia no sentido aristotélico de uma reflexão sobre as propriedades gerais do ser, numa visão metafísica; já no outro caminho, da objetividade entre parênteses, há um domínio das ontologias constitutivas, no qual "fazemos referência às condições de constituição daquilo que falamos" (MATURANA, 2001, p. 43), ou seja, à reformulação dessas condições de constituição do que observamos. Em geral, funcionamos em uma realidade sem parênteses, em que aquilo que falamos é totalmente ligado a uma objetividade. Essa objetividade está ligada à perspectiva pela qual observamos o nosso objeto, nos termos de uma objeti- 
vidade entre parênteses, e de maneira consensual - em que os elementos existentes são independentes do observador - e compartilhada na objetividade sem parênteses. Maturana (2001, p. 45) esclarece que, nesse último caminho explicativo, é necessário questionar qual é a operação de distinção que fazemos para definirmos cada emoção. Para o autor, uma emoção é definida em termos do domínio de ação no qual ela se insere, o qual se especifica pelas disposições corporais relacionadas a essa emoção. Nesse sentido, é pela observação dos movimentos corporais dos outros que é possível definir o domínio de ação. Dessa forma, as emoções são, por um lado, definidas em termos biológicos. Por outro, as relações humanas são, em grande medida, fundamentadas nas emoções, pois essas se atualizam na dinâmica das ações com os outros. Para Maturana (2001) a linguagem, base para a convivência humana, e as relações sociais se fundamentam nas emoções:

As emoções são centrais na evolução de todos os seres vivos, porque definem o curso de seus fazeres (...). O emocionar, o fluxo das emoções, vai definindo o lugar em que vão acontecer as coisas que fazem no conviver. Então, se uma pessoa se move, por exemplo, a partir da frustração, isso vai definir continuamente o espaço relacional na qual se encontra e o curso que vai ter seu viver. Se vive a partir da confiança, vai seguir um curso distinto. Assim, portanto, o que guia o fluxo do viver individual são as emoções e na constituição evolutiva também. (MATURANA - entrevista concedida a SACRAMENTO; VIEIRA, nov. 2004)

As emoções parecem guiar os movimentos dos corpos em uma constante construção nas interfaces social, cultural, cognitiva e evolutiva, provando assim o seu papel relevante na tomada de decisões. Nessa visão, o tipo de movimento emocional que leva uma pessoa a agir de certa forma determina como ela deverá interagir com o outro em dado espaço, no fluxo dos acontecimentos.

Maturana e Varela (1997) afirmam que nossos corpos devem ser compreendidos, ao mesmo tempo, como estruturas vivas e experienciais, em que interno e externo, biológico e fenomenológico estão em interação. O corpo, em constante devir, serve de base para a experiência e nos leva ao entendimento dos conceitos que nós mesmos construímos pela linguagem e pela cultura. Ao fazermos parte do mundo, colocamo-nos em uma posição indissociável a ele: somente produzimos significados para ele porque ele próprio é construto. Desse modo, pelo fato de entendermos o corpo como um modelo semântico que se molda no fluxo da vida cotidiana (GREINER, 2005), a tese da corporeidade sustenta que muitos dos conceitos que construímos surgem a partir de elementos advindos da tríplice corpo-mente-mundo. Essa fica evidenciada na forma como nos expressamos linguisticamente, tendo em vista que muitos dos conceitos que elaboramos emergem de nossas experiências, por meio de um sistema cognitivo altamente metafórico (LAKOFF; JOHNSON, 1980). Assim, mesmo em expressões altamente convencionais, como no caso de "Saramago é o maior escritor em Língua Portuguesa", temos uma metáfora conceptual (IMPORTÂNCIA É TAMANHO) que nos permite compreender e estruturar conceitos complexos e abstratos a partir de outros mais básicos, os quais são elaborados desde a nossa mais tenra idade (cf. SIQUEIRA, 2003). Para Mandler (2004), experiências recorrentes e básicas com o mundo formam a base da arquitetura semântica da criança, estabelecida ainda antes de ela começar a produzir linguagem. Nesse sentido é que se pode dizer que a corporeidade forma a base dos conceitos humanos mais fundamentais. Até mesmo tempo e espaço são conceitos estruturados devido à nossa experiência: atividades passadas estão atrás de nós ("Deixei para trás todas as minhas amarguras") e o futuro está logo ali, na nossa frente; uma casa pode ser grande demais para uma pessoa sozinha, enquanto um elevador que carrega oito pessoas pode ser muito pequeno quando lotado. Conceitos relacionados a emoções também têm lugar privilegiado nas teorias baseadas no realismo corpóreo: ao dizermos que alguém transborda de emoção, percebemos que essa pessoa caracteriza seu corpo como um recipiente no qual estão contidas todas as suas emoções, por exemplo.

Resquícios da tradição cartesiana, que separa a substância mental da física, ainda permanecem em nossa maneira de pensar, como quando dizemos que as emoções tomam conta de nós, ou que perdemos a cabeça em momentos de emoção intensa. A realidade 
pressuposta pelo cogito se reduz ao postulado de uma mente imaterial, base de toda a racionalidade. Contudo, já sabemos que, com a inserção do corpo no debate sobre a forma como pensamos, estabelecemos um caminho sem volta. Mesmo que ainda nos expressemos baseados nessa realidade estritamente racional, metafísica, tão enraizada em nossa tradição ocidental, nosso sistema cognitivo opera a partir das experiências de nossos corpos em interação na construção do nosso entendimento sobre o mundo.

A noção de corporeidade decorre do fato de sermos agentes ativos, com um corpo de determinado tipo, sustentado como experiência vivida e como objeto físico, a partir do qual estabelecemos as nossas percepções e nossos pensamentos em relação às nossas vivências no mundo. O diálogo - intersubjetivo - com outros corpos nos faz construir as realidades que tradicionalmente chamamos de objetiva e subjetiva. "O que podemos experienciar e como fazemos sentido do que experienciamos depende dos tipos de corpos que temos e das maneiras como interagimos com os vários ambientes nos quais habitamos" (JOHNSON, 1999, p. 81). É pelo engajamento com outros seres humanos que nos constituímos e que damos sentido à realidade que se constrói no movimento dos corpos no mundo. Para Maturana (2001, p. 100), “(...) sempre nos movemos (...) neste jogo de que na linguagem interagimos de modo que (...) se produzem no outro e em nós mudanças estruturais às quais somos constitutivamente cegos". Assim, essas mudanças estruturais levam à mudança na forma como nos encontramos com o outro e na maneira de perceber o mundo. Para o mesmo autor, a história de mudança estrutural de um organismo em interações é uma deriva estrutural:

A ontogenia de um ser vivo é uma deriva estrutural, na qual as mudanças estruturais que ocorrem são contingentes com as interações com o meio. Não são determinadas pelas circunstâncias do meio, mas são contingentes com elas, porque o meio apenas desencadeia no ser vivo mudanças estruturais. E vice-versa: o meio muda de maneira contingente com as interações com o organismo, e aquilo ao qual o observador irá se referir vai depender de onde esteja seu olhar. (MATURANA, 2001, p. 82)
Essa deriva nada mais é que o curso que a estrutura do organismo segue em consonância com as suas interações. As mudanças ocorridas se produzem a todo o momento, pois o contato do corpo com o meio é, também, inevitável - mesmo que ele esteja parado, a sua estrutura deve variar. Os comportamentos em relação ao outro decorrem das suas coordenações consensuais (MATURANA, 2001, p. 85): assim como a estrutura de um corpo se modifica em relação ao(s) outro(s), suas condutas são congruentes às condutas dos outros. Mas essa conduta interacional nem sempre é consciente: para Sellars (1963 [1991]), há dois tipos de percepção: (1) a percepção como "comportamento discriminatório", que dispensa o uso da linguagem e é manifesto por qualquer ser que seja capaz de processar informações; e (2) a percepção como "estar no espaço lógico das justificações", experimentado por seres capazes de expressar argumentos, opiniões, justificações em relação às percepções do primeiro tipo. Assim, para o autor, a percepção é, em primeira instância, puramente corpórea, elaborada por meio de inputs inconscientemente processados, dados pelas respostas corpóreas, e a percepção construtiva, em que há uma elaboração consciente do primeiro tipo de percepção, explorada em nível linguístico. Respectivamente, trata-se do "conhecer X" e do "entender X". O filósofo afirma que esses dois tipos de percepção não são a mesma coisa, embora estejam conectados. ${ }^{5}$

Seguindo essa concepção, Bezerra (2001) salienta que os seres têm a capacidade de atingir certos fins porque, de certa forma, sabem que tipo de comportamento adotar. Por exemplo, um bebê sabe (conhece) o cheiro de sua mãe, e por isso se acalma ao estar no colo dela. Trata-se do primeiro tipo de percepção, em que os seres sabem, instintivamente, como agir e como processar os inputs que se mesclam às suas percepções corpóreas através de "discriminação seletiva de estímulos do meio e da adequada utilização de recursos de que cada organismo dispõe" (p. 27). Segundo o mesmo autor, "em algum momento (...) às suas capacidades biológicas inatas irá se juntar uma outra, aprendida na prática social e na interação com outros humanos: o uso da linguagem e a capacidade de ingressar no jogo das justificativas" (p. 28) - trata-se, aqui, do segundo tipo de percepção, a 
que introduz o equipamento linguístico a fim de levar a criança a se reconhecer como um $E$, percebendo não só as suas próprias emoções, mas as dos outros, conseguindo designá-las e nomeá-las. Há, a partir desse ponto, não apenas a consciência de si, mas a consciência de si como sujeito que é capaz de comunicar algo e expressar opiniões, desejos, justificativas; consegue, portanto, atribuir sentidos às suas experiências (Bezerra, 2001).

Assim, o mundo, compreendido como um construto da objetividade entre parênteses, não está pronto: tudo aquilo que se relaciona a nós mesmos - tempo, espaço, emoções - faz parte das elaborações que fazemos em consonância com o movimento de nossos corpos. O realismo corpóreo, dessa forma, nega que exista uma descrição única para o mundo. Para Lakoff e Johnson (1999), isso talvez pareça uma forma de relativismo, mas não de tipo extremo, tendo em vista que deve dar conta de como o conhecimento real e estável é possível. Para os autores, há duas considerações a se fazer sobre esse relativismo: primeiro, "há conceitos incorporados diretamente, tais como conceitos de nível básico, de relações espaciais e de estrutura de eventos" (p. 96, grifo meu), e esses têm uma origem evolucionária e nos permitem agir bem em situações cotidianas; segundo, metáforas conceptuais primárias "tornam possível a extensão desses conceitos incorporados em domínios teóricos abstratos" (p. 96). Essas são construções delimitadas diretamente por nossas experiências. Exemplo disso é o conceito de AMOR, muitas vezes referido como CALOR, que emerge linguisticamente sob a forma de uma construção metafórica - como ocorre em "Nossa relação está cada vez mais quente". Do mesmo modo, a partir de metáforas altamente convencionais, novos e complexos mapeamentos metafóricos podem se estabelecer no intuito de tentar definir o significado de conceitos que emergem a todo o momento na vida cotidiana.

Apesar de esses conceitos estarem ligados ao domínio das emoções e dos sentimentos, eles não são concebidos em uma relação de igualdade; isto é, um conceito de emoção não equivale à própria emoção ou a um sentimento, mas é uma representação particular do que um indivíduo e/ou uma comunidade de fala elaboram e compreendem a respeito desses domínios.
Ao se fundamentar principalmente em uma matriz biológico-cultural da existência humana, Maturana (2001) a assume também para o domínio da emoção. Essa concepção é compatível com a abordagem defendida por Prinz (2004), para o qual as emoções são vistas como elementos desenvolvidos evolutivamente e construídos culturalmente. Por isso, esse autor considera que há duas perspectivas principais para explicar a origem das emoções. Para uma delas, emoções são produtos da seleção natural: são adaptações de acordo com a evolução humana. Há considerável acordo entre estudiosos dessa linha darwinista, de que há, de fato, emoções "básicas" (Ortony e Turner, 1990; Ekman, 1992). Seguindo o outro ponto de vista, as emoções seriam construídas socialmente, e poderiam variar interculturalmente (Rosaldo, 1984; Lutz, 1988; Damásio 1996; 2004). Segundo Prinz (2004), cada emoção que tem um nome é produto da natureza e também do desenvolvimento evolutivo. Desse modo, emoções são, ao mesmo tempo, evoluídas e construídas, e a dicotomia entre as duas abordagens não pode ser mantida.

Segundo Prinz (2004), não há nomes para emoções básicas - todas as emoções sobre as quais se fala são culturalmente informadas - e, portanto, construídas numa realidade entre parênteses. Enquanto se diz que há uma diferença entre emoções básicas e não básicas, acredita-se que essa diferença não é estrutural; todas as emoções são fundamentalmente semelhantes. Isso porque elas emergem a partir de percepções, desencadeadas a partir de dadas situações, e, por isso, caracterizadas de acordo com os aspectos culturais e sociais confrontados pelo indivíduo.

Contudo, uma emoção não é apenas o conjunto de sensações que a constitui; nem o evento emocional tem uma sequência causal fixa. Para Damásio (1996), as emoções podem ocorrer, de fato, como James (1884) as descreve (a saber: Evento > Precipitação > Interpretação > Emoção), mas os passos que as constituem tendem a ser interpostos, bem como uma filtragem desses estímulos acontece. Para o neurocientista, a cognição gerada pelo estado emocional não é totalmente confinada a imagens de estímulos e a mudanças corpóreas, como previa James, mas as emoções humanas também desencadeiam certas mudanças cognitivas que acom- 
panham as mudanças corpóreas: “(...) os sentimentos não têm origem necessariamente no estado real do corpo, mas sim no estado real dos mapas cerebrais que as regiões somatossensitivas constroem em cada momento" (DAMÁSIO, 2004, p. 122).

Nesse sentido, Damásio (1996; 2004; 2010) explica que sentimentos e emoções são processos distintos, mas entrelaçados ao mesmo tempo. Trata-se de um ciclo que se inicia no cérebro, com a percepção e o julgamento de um estímulo potencialmente capaz de causar uma emoção e, subsequentemente, desencadear uma emoção. $\mathrm{O}$ autor esclarece que o processo se espalha pelo cérebro e pelo corpo, construindo o estado emocional, e, a seguir, retorna ao cérebro para a parte de sentimento do ciclo, numa relação causal.

Emoções, numa visão neurobiológica, são tratadas como programas de ações complexas interligados à evolução. Damásio (2010) entende que as ações são complementadas por um "programa cognitivo que inclui certas ideias e modos de cognição, mas o mundo das emoções é, de modo amplo, aquele em que ações desempenhadas em nossos corpos, das expressões faciais e posturas a mudanças viscerais e no ambiente interno" (p. 109). Já os sentimentos de emoção são compreendidos como "percepções compostas do que acontece no corpo e na mente quando nos emocionamos" (DAMÁSIO, 2010, p. 109). Assim, sentimentos são imagens de ações ao invés de ações em si mesmas. As percepções chamadas de "sentimentos de emoções" são "baseadas na relação única entre corpo e cérebro que privilegia a interocepção". Para o autor, há outros aspectos do corpo que são representados em sentimentos emocionais, mas "a interocepção domina o processo e é responsável por aquilo que designamos como o aspecto sentido [felt] daquelas percepções" (p. 110).

$\mathrm{Na}$ atribuição de nomenclaturas para emoções, os significados ligados ao conceito desencadeado pela expressão linguística podem suscitar interpretações diversas, ainda mais quando é analisada em um contexto comunicativo. A classificação linguística de uma emoção básica depende, então, da sua inserção em uma categoria construída no momento da interação, e essa não pode ser definida a priori. Assim, a natureza dos corpos que possuímos e a forma como nos relacionamos com outros corpos têm papel decisivo na definição do que são emoções e por que vemos algumas delas como sendo mais básicas do que outras, ditas mais complexas. Além disso, o fluxo constante de interações em que o corpo se insere permite um processo de inferenciação que se inicia quando ainda não há consciência das percepções sobre o mundo em construção e só vêm à tona, na forma de expressões linguísticas, ao se atingir certa compreensão das próprias percepções, designando aí o que compreendemos por sentimentos de emoção.

Portanto, é pela interação com outros corpos em dado ambiente que temos, primeiro, um saber ainda instintivo do que são emoções e sentimentos; segundo, que os entendemos como domínios distintos - sentimentos de fundo (manifestações sutis, como o mal-estar), emoções básicas (como a raiva) e emoções sociais (como o nojo) - porque esse comportamento discriminatório é elaborado via processos inferenciais que levam à construção dos conceitos expressos em nível linguístico. É no jogo das justificativas e no uso da linguagem que passamos a explicitar a nossa concepção sobre as emoções que sentimos - isto é, expressamos em palavras os nossos sentimentos de emoção.

\section{Uma reflexão sobre a conceptualização de emoções}

Mais do que um fenômeno meramente perceptual, as emoções como construtos psicológicos e neurofisiológicos são produtos das relações intersubjetivas na cultura e na sociedade. Diz-se que emoções evoluíram não apenas como sentimentos conscientes, mas como respostas a estados mentais e corporais. Na verdade, os sentimentos conscientemente revelados são modelados na e pela linguagem (com a interferência das interações do corpo com o meio), através da qual se manifestam os modos como determinadas emoções são definidas significativamente e compartilhadas em uma sociedade.

De maneira geral, emoções possuem um caráter universal: elas estão presentes em todas as culturas do mundo, são expressas em maior ou menor grau, e muitas delas parecem ser mais básicas do que outras. Contudo, não se pode dizer que há um vocabulário básico que poderia descrever as emoções, o qual poderia ser 
encontrado em todas as línguas do mundo, como sustenta Wierzbicka (1996), por exemplo; a conceptualização de uma emoção é reorganizada a partir de padrões e de aspectos reconhecidos pela cognição incorporada; assim, mesmo que uma emoção não tenha sido ainda designada em dada cultura, não significa que as pessoas não a percebam. Se esse fosse o caso, a existência do vocábulo "saudade" na língua portuguesa significaria que só quem fala essa língua seria capaz de sentir e expressar essa emoção. Contudo, mesmo que "saudade" só existisse em português - e há indícios de que em outras línguas existam palavras correspondentes a uma tristeza, ou melancolia, provocada pela ausência, como no polonês tesknota, por exemplo - seria estranho pensar que apenas uma parcela ínfima da população mundial é capaz desse sentimento.

Há também uma hipótese de que palavras seriam apenas rótulos para expressões linguísticas relacionadas a conceitos, por exemplo. Há emoções para as quais não há nomes específicos, e muitas vezes é preciso criar descrições para expressar de forma aproximada o que sentimos. Tal constatação poderia enfraquecer a bem conhecida hipótese Sapir-Whorf (SAPIR, 1929 [1958]; WHORF, 1940), a qual pode ser associada a dois princípios: em sua instância forte, preconiza que o pensamento é determinado pela língua (determinismo linguístico); de maneira fraca, o relativismo linguístico assume que pessoas que falam línguas diferentes percebem e pensam sobre o mundo de modos diferentes. Em linhas gerais, o mundo é inconscientemente moldado de acordo com a língua utilizada por uma comunidade de fala, em um acordo implícito e tácito (WHORF, 1940, p. 213-214).

Nossa língua materna pode, de fato, dirigir e moldar o nosso pensamento, mas Boroditsky (2011) demonstra que o caminho inverso também é possível. Segundo a pesquisadora, a língua tem um papel causal em modelar a cognição, e a forma como as pessoas falam pode modificar a maneira de pensar. Concomitantemente, o modo como pensamos sobre determinado objeto, como as emoções, reflete-se na língua em uso. Assim, cada língua traz uma visão de mundo e conhecimento que se desenvolveu por muito tempo em uma cultura, cada qual com sua forma de perceber, categorizar e formular significados.
Vocábulos e expressões linguísticas, como veremos, ajudam-nos a construir novos conceitos, ao mesmo tempo em que limitam nossas possibilidades de descrever aspectos humanos abstratos, como no caso de emoções. Muitas vezes, o que percebemos pelos nossos sentidos não tem nome; sentir "uma coisa" por alguém pode significar a experimentação de algo que se tenta acomodar em uma linha tênue entre o que entendemos como "afeição", "paixão" e "amor", e ainda pode estar perto do que classificamos como um mero "incômodo" pela presença do outro. O entre-sentimento que surge, e que por vezes não conseguimos nomear, passa a reestruturar-se a fim de que, pela infinita quantidade de emoções que sentimos ou que ainda não conhecemos, possa caber em nosso limitado léxico. Se não é possível definir com clareza o que é dada emoção que nos arrebata, partimos para a tessitura de relações com o nosso grupo social e cultural, numa tentativa de (res)significar as experiências relacionadas a determinadas emoções.

Sendo a linguagem um guia para o sentido (cf. FAUCONNIER, 1994), a forma linguística orienta as tarefas semântico-cognitivas, sociais e culturais da linguagem. Por meio dela, os indivíduos compartilham os processos inerentes às emoções a fim de caracterizar o sentido delas no mundo. Por isso, ao interagirem uns com os outros, os interlocutores estão ao mesmo tempo partilhando informações, as quais são reelaboradas intersubjetivamente a cada novo ato comunicativo. Somente através do trato social e pelas relações estabelecidas intersubjetivamente é que o sentido se renova: as práticas interativas revelam o desejo de reconstrução dos sentidos para a realidade e, consequentemente, para as próprias emoções. Isso não significa dizer que um novo conceito é elaborado no contato com o outro; na verdade, os conceitos advindos da memória enciclopédica que cada interlocutor acessa durante a comunicação são os responsáveis pela alteração e pela construção de conhecimentos - e esses atos ocorrem mesmo que o indivíduo, em sua instância ontogenética, esteja "à deriva" (Maturana, 2001), ou seja, apenas levado pelo fluxo dos acontecimentos. Para Greiner (2005), "esse fluxo incessante constrói novos vocabulários que são muito mais que nomes vagando pelo mundo. Esse 'novo voca- 
bulário' reflete modos de organização dos pensamentos que organizam as ações corpóreas e o mundo" (p. 55).

A construção de conceitos em um mundo intersubjetivo pressupõe o partilhar e o adaptar experiências pela linguagem. Essas noções são baseadas em pressupostos da Linguística Cognitiva, como: (a) a linguagem integra a cognição, e não é um módulo dela; (b) a linguagem se fundamenta em processos cognitivos, sociais e culturais, por isso sendo estudada na interação e no contexto em que a conceptualização ocorre, bem como a categorização, o processamento inferencial e do impacto das experiências individuais, sociais e culturais. (LAKOFF; JOHNSON, 1999). As relações de objetividade e subjetividade são construídas e, por conseguinte, também o são os conceitos. Sendo entidades ditas abstratas, nossas emoções são constituídas corporal e culturalmente pelas interações sociais e dinâmicas, revelando-se em construções metaforizadas.

Immordino-Yang (2010) sustenta que os processos psicológicos são pensamentos interrelacionados e sentimentos sobre o mundo e sobre o $\mathrm{Eu}$, que se mostra instável no contexto dinâmico das estruturas conceptuais. Para a autora, essas estruturas conceptuais evoluíram em resposta a mudanças internas e a circunstâncias externas. Desse modo, as emoções tais como as elaboramos conceptualmente são resultado de avaliações, ou interpretações, que fazemos sobre o que sentimos e sobre as reações dos outros a partir de um contexto dinâmico. De fato, para ImmordinoYang, o estímulo emocionalmente definido - isto é, aquele que resulta em interpretação sobre as emoções que se passam com o outro - não está no mundo, mas é "um estado de conhecimento concebido a partir de experiências passadas, elas mesmas subjetivamente percebidas e memorizadas, sobre o que supomos estar acontecendo na mente da outra pessoa, como ligadas indiretamente por nossa percepção de suas circunstâncias e ações" (p. 2). Dessa forma, a conceptualização das emoções passa a existir somente pela presença do outro e por causa de suas manifestações, que podem ser observadas não apenas linguisticamente, mas através de posturas corporais, da velocidade e da forma como executamos nossos movimentos, do tom de voz empregado, da prosódia de nosso discurso quan- do comunicamos pensamentos relacionados - ou não - a nossos estados emocionais.

Ao abordar essas emoções como processos psicológicos intersubjetivos que se organizam dinamicamente durante o curso de uma troca social, a emoção do participante que se desvela é exteriorizada, e ganhamos uma janela para seus processos. Essa janela permite analisarmos não apenas as partes psicológicas componentes de sua experiência consciente, mas as relações entre essas partes, e os processos pelos quais ele representa mentalmente essas relações. (IMMORDINO-YANG, 2010, p. 2)

Através da ideia de que nossas emoções são construídas intersubjetivamente, via interpretação do que sentimos e também dos estímulos emocionais lançados pelo outro, adotamos a visão de que conceitos de emoções são, ao mesmo tempo, potencialmente universais e culturalmente construídos. Designa-se universal devido à faculdade de racionalização, ou interpretação das próprias emoções, via experiência, inerente a todos os seres humanos; e é cultural por ser mediado pelas estruturas de significado e de compreensão que se situam social e historicamente.

É importante ressaltar que, mesmo sendo verdade que é a partir do corpo que elaboramos grande parte dos nossos conceitos, ainda assim nosso pensamento oscila entre essa perspectiva e a de um realismo extremo. Acreditamos que a influência cartesiana ainda hoje esteja marcada em nossa forma de entender o mundo e, por vezes, pensamos nossas próprias emoções como separadas da racionalidade, justamente porque essa visão de mundo é culturalmente transmitida. Todavia, a influência cultural com predominância de uma razão isolada de suas percepções tem lugar na nossa perspectiva sobre emoções, o que nos leva a organizarmos certos conceitos como se esses fossem suficientes em si mesmos. O papel do corpo para a constituição de conceitos de emoções é inegavelmente fundamental, já que a maioria dos significados relacionados a conceitos que emergem na fala cotidiana é marcada pela influência das experiências desse corpo em si mesmo, com o mundo e com outros corpos ao longo de nossas vidas. 


\section{Notas}

1. DEWEY, J. Experience and nature. Chicago: Open Court, 1925.

2. MERLEAU-PONTY, M. Fenomenologia da percepção. São Paulo: Martins Fontes, 1999 [1962].

3. A cognição off-line constituirá o contexto off-line, que pode ser compreendido como o conjunto de elementos experienciais e relevantes que emerge a partir da memória enciclopédica, ou memória de longo prazo, durante a interação.

4. Tomaremos a noção de self, segundo Greiner (2005), como ligada ao sujeito como epicentro do conhecimento e da cognição, da experiência e da ação, em que não se pressupõe um observador desencarnado, nem um mundo existente apenas na mente de alguém.

5. Tais tipos de percepção parecem estar em consonância com a noção de "ideia de ideias", de Damásio (2004), que "abre caminho para a representação de relações e para a criação de símbolos” (p. 228). Assim, na definição da espécie mais básica do self há uma ideia, mas uma "ideia de segunda ordem". Essa teria por base a relação de duas ideias de primeira ordem: uma delas seria do objeto cuja percepção estamos construindo, e a outra seria do nosso corpo à medida que é modificado pela percepção do objeto. Temos, então, a relação entre o objeto de que se tem percepção e o corpo modificado pela percepção.

\section{Referências}

BEZERRA Jr., Benilton. O lugar do corpo na experiência do sentido: uma perspectiva pragmática. In: BEZERRA JR., B.; PLASTINO, C. A. (Org.). Corpo, afeto, linguagem: a questão do sentido hoje. 2001, p. 13-42.

BORODITSKY, Lera. How language shapes thought: the languages we speak affect our perceptions of the world. In: Scientific American. February, 2011, p. 63-65.

DAMÁSIO, Antonio. O erro de Descartes: emoção, razão e cérebro humano. Trad. portuguesa de Dora Vicente e Georgina Segurado. São Paulo: Companhia das Letras 1996.

. Em busca de Espinosa: prazer e dor na ciência dos sentimentos. São Paulo: Companhia das Letras, 2004.

Self Comes to Mind: constructing the conscious brain. London: William Heinemann, 2010.

EKMAN, Paul. An argument for basic emotions. In: Cognition and Emotion 6, 1992, p. 169-200.

EVANS, Vyvyan; GREEN, Melanie. Cognitive Linguistics: an introduction. Edinburgh: Edinburgh University Press, 2006.
FAUCONNIER, G. Mental Spaces. Cambridge: Cambridge University Press, 1994.

GIORDANI, Rubia Carla Formighieri. O corpo sentido e os sentidos do corpo anoréxico. Rev. Nutr. Campinas, v. 22, n. 6, Dec. 2009, p. 809-821.

GREINER, Christine. O corpo: pistas para estudos interdisciplinares. São Paulo: Annablume, 2005.

HARDER, Peter. Partial Autonomy. In: JANSSEN, Theo; REDEKER, Gisela. (eds.). Cognitive Linguistics: foundations, scope, and methodology. Cognitive Linguistics Research 15. New York: Mouton de Gruyter, 1999, p. 195-222.

IMMORDINO-YANG, Mary Helen. Toward a Microdevelopmental, Interdisciplinary Approach to Social Emotion. In: Emotion Review, 2010, p. 1-4.

JAMES, William. What Is an Emotion? In: Mind, 9,1884, p. 188-205.

JOHNSON, Christopher. Metaphor vs. conflation in the acquisition of polysemy: the case of see. In: HIRAGA, M.; SINHA, C.; WILCOX, S. (Eds.). Cultural, Psychological and Typological Issues in Cognitive Linguistics. Current Issues in Linguistic Theory. V.152. Amsterdam: John Benjamins, 1999, p.155-169.

KÖVECSES, Zoltán. Metaphor in Culture: universality and variation. Cambridge: Cambridge University Press, 2005.

Metaphor. A Practical Introduction. Second edition. Oxford: Oxford University Press, 2010a.

. A new look at metaphorical creativity in cognitive linguistics. In: Cognitive Linguistics 21-4, 2010b, p. 663-697.

Metaphor, creativity, and discourse. In: D.E.L.T.A., 26: Metaphor and cognition. Vol. especial, $\mathrm{n}^{\circ}$ esp., 2010c, p. 719-738.

Recent developments in metaphor theory: Are the new views rival ones? In: Review of Cognitive Linguistics. Vol. 9, No 1, 2011, p. 11-25 (15).

LAKOFF, George. Women, Fire and Dangerous Things: What Categories Reveal About the Mind. Chicago: University of Chicago Press, 1987.

Cognitive Semantics. In: ECO, U.; SANTAMBROGIO, M.; VIOLI, P. Meaning and Mental Representation. Indiana University Press, 1988, p. 119-154.

LAKOFF, G.; JOHNSON, M. Metaphors We Live By. Chicago: The University of Chicago Press, 1980.

Philosophy in the Flesh: the Embodied Mind and Its Challenge to Western Thought. New York: Basic Books, 1999. 
LAKOFF, G.; TURNER, M. More than a Cool Reason: a Field Guide to Poetic Metaphor. Chicago: Chicago University Press, 1989.

LUTZ, Catherine. Unnatural emotions. Chicago: Chicago University Press, 1988.

MANDLER, Jean. The foundations of mind: origins of conceptual thought. Oxford: Oxford University Press, 2004.

MATURANA, H. Cognição, ciência e vida cotidiana. Organizado e traduzido por Cristina Magro e Victor Paredes. Belo Horizonte: Ed. UFMG, 2001.

MATURANA, H. R; VARELA, F. J. De máquinas e seres vivos: Autopoiese: A organização do vivo. Tradução: Juan Açuña Llorens. Porto Alegre: Artes médicas, 1997.

ORTONY, Andrew; TURNER, Terence J. What's basic about emotions? In: Psychological Review. Vol. 97, $\mathrm{n}^{\circ}$ 3, 1990, p. 315-331.

PRINZ, Jesse. Which emotions are basic? In: EVANS, D.; CRUSE, P. Emotion, Evolution, and Rationality. Oxford University Press. 2004, p. 69-87.

ROHER, Tim. Pragmatism, Ideology and Embodiment: William James and the Philosophical Foundations of Cognitive Linguistics. In: SANDRIKLOGOU; DIRVEN (eds.) Language and Ideology: Cognitive Theoretical Approaches. Amsterdam: John Benjamins, 2001, p. 49-82.

ROSALDO, Michelle. Toward an Anthropology of Self and Feeling. In: Seweder, R.; LeVine, R. (Orgs.). Culture Theory. Essays on Mind, Self and Emotion. Cambridge University Press: 1984, p. 137-157.

SACRAMENTO, M. H.; VIEIRA, A. J. H. Entrevista: Humberto Maturana. In: Revista Humanitates. Vol. I, no 2, Novembro de 2004. Disponível: http://www. humanitates.ucb.br/2/entrevista.htm. Acesso em 10/06/2010.

SAPIR, E. 'The Status of Linguistics as a Science' (1929). In: SAPIR, E. Culture, Language and Personality (ed. D. G. Mandelbaum). Berkeley, CA: University of California Press, 1958, p. 65-77.

SELLARS, Wilfrid. Science, Perception and Reality. Atascadero, CA: Ridgeview Publishing Company, 1963 [1991].

SINHA, Chris. Grounding, mapping and acts of meaning. In: JANSSEN, Theo; REDEKER, Gisela (eds.) Cognitive Linguistics: Foundations, Scope and Methodology. Berlin: Mouton de Gruyter, 1999, p. 223-255.

SIQUEIRA, Maity. As metáforas primárias na aquisição da linguagem: um estudo interlinguístico. Tese de doutorado. Pontifícia Universidade Católica do Rio Grande do Sul. 2003.

VARELLA, Francisco J.; THOMPSON, Evan; ROSCH, Eleanor. The Embodied Mind: cognitive science and human experience. Massachusetts Institute of Technology, 1991.

VEREZA, Solange Coelho. Articulating the conceptual and the discursive dimensions of figurative language in argumentative texts. In: D.E.L.T.A., 26: especial, 2010, p. 267-284.

WIERZBICKA, A. Semantics: Primes and Universals. Oxford University Press, Oxford, 1996.

WILSON, Margaret. Six Views of Embodied Cognition. In: Psychonomic Bulletin \& Review, 9 (4) 2002, p. 625636.

WHORF, B. L. Science and Linguistics. In: Technology Review 42 (6), 1940, p. 229-231.

Recebido em: 02/06/2015 Aceito em: 22/09/2015 
